\title{
A Study of the Inaugural Address of John F. Kennedy From the Perspective of Appraisal Theory
}

\author{
Yan Tan \\ Chongqing Normal University, China
}

\begin{abstract}
An Inaugural Address is a speech made by a speaker when he or she assumes a new position, stating his or her position, views and policies in light of domestic and international political and economic situations. Based on Martin's Appraisal Theory, this paper mainly uses the three subsystems of Appraisal Theory: Attitude, Engagement, and Graduation to explore and analyze the evaluative devices in Kennedy's Inaugural Address and its expression of the speaker's views and attitudes, and to fully reveal the reasons for the enduring popularity of this speech.
\end{abstract}

Index Terms-Inaugural Address, Appraisal Theory, Attitude, Engagement, Graduation

\section{INTRODUCTION}

Political speech is a kind of speech in which politicians expound their own or their political parties' ideas and opinions on domestic and foreign affairs and other national affairs, which is becoming increasingly popular in modern society (Bao, 2012). The Inaugural Address of the President of the United States contains unique personal political opinions and implies a major ideology and sense of national power. In addition to clarifying their political views and positions, the most important thing for the speaker is to inspire the public and raise morale, which has a high interpersonal significance, so the importance and research value of presidential Inaugural Addresses are self-evident.

This area has been extensively explored and studied by scholars both at home and abroad. For example, after a qualitative study of the British finance minister's financial speech, Wei Dan (2009) found the role of the engagement system in coordinating the negotiation between the speaker and multiple voices; Xu Jiakun (2010) used the Appraisal Theory to analyze President Obama's speech in Shanghai and tested the feasibility of Appraisal Theory in political speeches; Li Huifang (2010) analyzed Obama's election victory speech in terms of attitude and graduation subsystems, demonstrating that Appraisal Theory is an effective tool for justifying speakers' positions and providing a new perspective for interpreting political discourse. All these studies fully prove the effectiveness of Appraisal Theory in analyzing political speeches and are worthy of reference. This paper uses John F. Kennedy's Inaugural Address as a corpus, and mainly uses three subsystems of the Evaluation system to analyze the evaluation tools in the discourse and how these evaluation tools express the speaker's attitude, position and viewpoint, in order to fully and completely reveal the reasons for the enduring popularity of this speech.

\section{THEORETICAL BACKGROUND}

Halliday, a famous linguist, founded Systemic Functional Linguistics. Systemic functional linguistics considers language as a social semiotic with meaning potential, and believes that language as a social symbol has three major meta-functions: ideational, interpersonal, and discourse functions. Martin et al. saw the limitations of the three meta-functions in the practice of discourse analysis, and in the 1990s, they further expanded Halliday's interpersonal function and proposed the Appraisal Theory, which provided a new lexical-grammatical framework for the study of interpersonal meaning (Tong, 2015). Martin (2003) argues that the appraisal is about evaluation, i.e. the various attitudes negotiated in discourse, the intensity of the emotions involved, and the various ways of indicating value and allied readers. Appraisal refers to interpreting and explaining the deeper meaning behind language by analyzing its surface meaning. The Appraisal consists of three major subsystems: attitude, engagement, and graduation. At the same time, each subsystem contains its subsystem (Wang, 2001).

\section{APPRAisal ANalysis of KenNedy's InAUgural AdDRESS}

Kennedy's inaugural address, considered one of the most brilliant speeches in American history, was delivered after the Second World War, when the two camps of capitalism and socialism were in the midst of a cold war. The United States, as the most powerful country in the capitalist world, openly asserted itself as the head of the capitalist camp and launched a confrontation with the socialist countries. Against this historical background, Kennedy won the election, was sworn in as the 35th President of the United States, and gave his inaugural address, calling on people all over the world 
to fight for freedom and democracy. He masterfully used his linguistic skills to capture the hearts and minds of his audience, thus gaining spiritual resonance and emotional support.

\section{A. Attitude Subsystem}

The attitude subsystem plays an important role in Appraisal theory. Attitude resources can be used to evaluate things, human character traits, and feelings, and it contains three categories: affect, judgment, and appreciation, which are emotional responses, moral judgments, and aesthetic character assessments of actions, texts/processes, and phenomena from the perspective of language users. The attitude resources in President Kennedy's inaugural address are summarized as follows. From Table 1, we can see that Kennedy's speech has approximately 45 judgment resources; 20 resources expressing affect; and 40 appreciation resources.

TABLE 1

ATTITUDE RESOURCE STATISTICS OF PRESIDENT KENNEDY'S INAUGURAL ADDRESS
\begin{tabular}{|c|c|c|c|c|}
\hline & Judgment & Affect & Appreciation & Total \\
\hline John. Kennedy & 45 & 20 & 40 & 105 \\
\hline
\end{tabular}

\section{Judgment}

Judgment refers to the evaluation of the behavior of a person or group of people according to certain criteria, including their actions, words, beliefs, motives, etc. In other words, people's behavior can be classified as ethical or unethical, legal or illegal, socially acceptable or unacceptable, etc. This category involves social esteem, which is determined by the normality, competence, and tenacity of speech acts, and social sanction, which is determined by the veracity and perseverance of speech acts. With regard to the resources of judgment, the following analysis can be made from these fragments of the article.

Examples:

'We observe today not a victory of party, but a celebration of freedom-symbolizing an end, as well as a beginning - signifying renewal, as well as change.' The speech's historical significance was emphasized through a positive, affirmative judgment of the presidential campaign's victory, which in turn encouraged the American people.

'Not because the Communists may be doing it, not because we seek their votes, but because it is right.' The word "right" is a positive judgment of the act of helping the poor overcome hardship. The language has strong positive overtones and proclaims the American humanitarian spirit.

'Those who foolishly sought power by riding the back of the tiger ended up inside.' The word foolishly is the irony of the act of a donkey in a lion's side that will finally ended up in the tiger's mouth, judging the act foolishly, reflecting the fact that we would not do such a foolish act.

'If a free society cannot help the many who are poor, it cannot save the few who are rich.' The first "cannot" acts as a modal verb in the conditional clause, while the second "cannot" indicates a determination of the resulting incapacity, demonstrating a liberal society's concern for the relief of the poor and proclaiming the fairness of American democratic society.

From the above examples, we can see that the audience of political speeches is mostly the general public, and the speaker's speech aims to impress the audience and gain their support. Therefore, the use of positive evaluation resources in Kennedy's Inaugural Address not only shows Kennedy's deep feelings for the people and his desire to unite the people and get their support, but also gives the audience inspiration and encouragement, which makes the audience more receptive to the speech content.

\section{Affect}

Speeches, especially political speeches, are usually emotionally charged with propaganda and persuasion, and they are also an expression of the speaker's emotional attitude (Yang, Yin, 2009). Emotion is the core of the whole attitude system and refers to someone's emotional reaction to an objective existence, which can be a behavior, a process, or an objective phenomenon. Affect can be expressed both through mental and relational processes and through lexical means that indicate attitudes. In English, such words are mostly verbs, adjectives, adverbs and nouns that express feelings. As can be seen in Table 1, there are roughly 20 occurrences of resources expressing emotion in Kennedy's speech, such as:

'We shall not always expect to find them supporting our view. But we shall always hope to find them strongly supporting their own freedom.' The word "but" connecting the two juxtapositions shows Kennedy's attitude toward other nations, both "desired" and "undesired" actions, by which he argues that nations with different ideologies can still have a common goal of pursuing freedom.

'This Hemisphere intends to remain the master of its own house.' The phrase "intends to" shows the determination and will of the United States to support other countries in gaining independence and seeking freedom.

'I do not shrink from this responsibility - I welcome it.' The words "escape" and "welcome" are antonyms, but they are used in the same sentence to show Kennedy's attitude toward preserving freedom: treat it as a responsibility and try to fulfill it.

From the above analysis, we can see that Kennedy's Inaugural Address contains a large number of emotional resources for the people, and the highest proportion is positive emotional resources. It can be seen that the emotional 
response brought by positive words can make the speaker and the audience interact with each other emotionally and create a good atmosphere.

\section{Appreciation}

Appreciation system belongs to the category of aesthetics, which is the judgment of the value of things and phenomena, with equally positive and negative connotations. Appreciation is mainly the evaluation of discourse, abstract things or natural things. It is divided into three aspects, namely reaction, composition and valuation. From Table 1, it can be concluded that in Kennedy's inaugural address, appreciation resources appear roughly about 40 times, for example.

'For I have sworn before you and Almighty God the same solemn oath our forebears prescribed nearly a century and three quarters ago.' These three adjectives are highly religious, in line with the speeches of American presidents in the past, as an indication of the speaker's holy and firm determination.

'The world is very different now. For man holds in his mortal hands the power to abolish all forms of human poverty and all forms of human life. And yet the same revolutionary beliefs for which our forebears fought are still at issue around the globe.' The word "different" shows the great changes in the current international situation; the word "mortal" praises the greatness of man's own power, in line with the humanistic thought in American culture; the phrase "same revolutionary" shows the persistence and tenacity of Americans in the process of striving for their ideals in all generations.

'Can we forge against these enemies a grand and global alliance, North and South, East and West, that can assure a more fruitful life for all mankind?' The portrayal of the alliance policy here highlights the prospect of the future era with stronger effect. Kennedy is standing in a friendly and optimistic manner in the favor of his own country and other countries, making a positive judgment and evaluation of the present relationship and future of the United States and the countries of the world.

From the above analysis, it can be seen that Kennedy fully utilized the appraisal resources of judgment, affect and appreciation to appeal and rally the people in his Inaugural Address, thus reflecting his ambitious political ideals and governance strategies.

\section{B. Engagement Subsystem}

Engagement systems are closely related to attitude systems, and Engagement resources are employed to regulate the speaker's own responsibilities and obligations involved in expressing a point of view (Liu, Luo, 2017). Engagement systems are used to systematically describe those types of meaning that construct a given texts or discourse as a heterogloss site that mixes discourses about prior discourses, discourses of different perspectives, and discourses that are expected to be produced. In short, it is the means by which language users use engagement to regulate or shift their otherwise required responsibilities and obligations for what is said.

According to Martin, engagement can be divided into monogloss and heterogloss (Martin, 2005). Monogloss refers to the appraisal activity implemented through a single person's voice. Monogloss has reference to dialogicality and is mainly implemented by projecting the voice, which aims to free the language user from or shirk responsibility and make the discourse appear objective (Wang, 2001). Heterogloss is divided into disclaim, proclaim, entertain, and attribute. Disclaim and proclaim are dialogic contraction, while entertain and attribute are dialogic expansion. By contracting semantically, the speaker affirms his or her own views and rejects other views that contradict his or her own; by expanding semantically, the speaker leaves some room for other voices so that his or her own views are not challenged and draws closer to the audience.

(1) The use of monogloss resources is quite frequent in Kennedy's inaugural address, for example:

Example 1:

'For I have sworn before you and Almighty God the same solemn oath our forebears prescribed nearly a century and three quarters ago. I do not shrink from this responsibility-I welcome it. I do not believe that any of us would exchange places with any other people or any other generation.' Both of these lines are expressions of President Kennedy's personal emotions, appearing at the beginning and end of the speech, respectively. There is a reason for this arrangement: the monogloss is used at the beginning to introduce the speech and express the importance he attaches to the inaugural address. The use of the monogloss at the end is to enhance the subjective attitude, to express his confidence and will as clearly as possible to win the encouragement of the people, and to win the encouragement of the public.

Another manifestation of the monogloss is the extensive use of the personal pronouns we, us and our. In Kennedy's inaugural address, most of the small sentences use the first person plural "we", "us" and "our ". Like the table shows:

TABLE 2

THE PERSONAL PRONOUNS

\begin{tabular}{|c|c|c|c|c|c|}
\hline The personal pronouns & $\begin{array}{c}\text { First person (I, } \\
\text { my) }\end{array}$ & $\begin{array}{c}\text { First person plural } \\
\text { (we, us, our) }\end{array}$ & $\begin{array}{c}\text { Second person } \\
\text { (you, your) }\end{array}$ & $\begin{array}{c}\text { Third person } \\
\text { (it, its, his) }\end{array}$ & $\begin{array}{c}\text { Third person plural } \\
\text { (they, them, their) }\end{array}$ \\
\hline $\begin{array}{c}\text { Quantity/ } \\
\text { percentage }\end{array}$ & $8 / 7.5 \%$ & $64 / 59.8 \%$ & $10 / 9.3 \%$ & $17 / 15.9 \%$ & $8 / 7.5 \%$ \\
\hline
\end{tabular}


According to statistics, the first person plural was used most frequently in Kennedy's speech. "We" was used 31 times, "our" was used 21 times, and "us" reached 12 times. The first person plural is used mainly and 64 times. This can pull the audience down to the speaker's side, put them on the same footing, build interaction and feel close to them, and create empathy. Specific examples are as follows.

Example 2:

'We dare not forget today that we are the heirs of that first revolution.

This much we pledge - and more.

United there is little we cannot do in a host of cooperative ventures. Divided, there is little we can do- for we dare not meet a powerful challenge at odds and split asunder.

Let both sides explore what problems unite $\underline{\text { us }}$ instead of belaboring those problems which divide $\underline{\text { us. }}$.'

From the above examples, it can be concluded that the use of a large number of first-person plural brings the psychological distance with the audience closer, makes the speaker's ideas more acceptable to the audience, and makes it easier to win the audience's approval and support. The pronoun "we" refers to both the speaker and the entire American audience as a way to evoke a sense of community and responsibility among the entire American public, which is highly inflammatory. In addition, "We" can bring the president closer to the people than "I", showing that the president himself and the people belong to the same joint effort as a whole, thus enhancing the credibility of the words, which is not only conducive to the unity of national consciousness, but also makes the speech more inflammatory and appealing, and better encourages the people.

(2) In addition to using monogloss measures, President Kennedy also used heterogloss measures to reflect dialogicality, to regulate his responsibility or obligation to speak or to enhance the credibility of his words, and to make them appear objective and fair. Heterogloss resources include dialogic contraction and dialogic expansion. For example:

Example 1:

'the command of Isaiah - to "undo the heavy burdens ......'

This phrase belongs to dialogic contraction and is quoted from the book of Isaiah, chapter 58, verse 6 of the entire Old Testament of the Bible. By using heterogloss measures and quoting the classic words of the book, it can make the speaker's point more credible and make the listener agree with his or her point of view at a greater level. Since religious language is mostly strongly inflammatory, its use here facilitates a call for unity between the two sides to meet the challenge together. It can also make one's point of view more objective, accurate and convincing, thus achieving empathy with the listener.

Example 2:

'for whatever period is required - not because the Communists may be doing it.

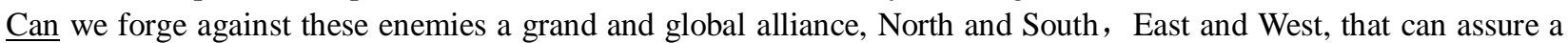
more fruitful life for all mankind? Will you join in that historic effort?'

First, the excerpted text here shows Kennedy's negotiability of propositional meaning by using various forms of linguistic resources such as modal verbs (can, will) and rhetorical phrases to express "entertain". By using these devices, speakers construct the discourse more openly, more receptive to different perspectives, and more negotiable with different gestures. Yaping Zeng (2009) argues that the use of low and medium-value modals can make one's propositions less coercive and make the message more acceptable to the audience, thus increasing the chances of the message being approved by the audience and avoiding criticism and challenge from the audience. Similarly, systemic functional linguistics argues that modal verbs of low and medium magnitude have the function of expressing relative attitudes, leaving room for what the speaker has said ( $\mathrm{Hu}, \mathrm{Zhu}, 2005)$.

Second, rhetorical questions (both rhetorical and interrogative) also introduce heterogloss measures, indicating that the speaker acknowledges the possibility of multiple points of view. For instance, in Example 2, Kennedy includes the affirmative answer-"We can surely unite the South and the North, the East and the West, and melt them into a great and global union...I trust that you are willing to participate in this historic endeavor " is included in the question, thus indicating that this is the inevitable and only option, while expressing a strong confidence and determination. The use of rhetorical interrogatives creates more atmosphere and triggers audience buy-in than ordinary statements.

\section{Graduation Subsystem}

The gradation subsystem is closely related to the attitude subsystem and the engagement subsystem because the former directly modifies the latter two and indicates the interpersonal degree of the latter two. The distinction between upward or downward degrees is called "force", and the description of non-gradable categories such as people and objects is called "focus". The greatest difference between political discourse and other discourse lies in the sharpness of the point of view, the firmness of the position, and the strong rendering. In the grading system of Inaugural Addresses, there are more occurrences of discourse potential than focus, and among the discourse potential, there are more strong than weak. This reflects the speaker's use of cascading resources to amplify his or her point of view and to reinforce the emotional or judgmental meaning expressed. An important reason for the success of President Kennedy's inaugural address was the repeated use of strong resources. For example:

(1) 'To those old allies, To those new States, To those peoples in the huts and villages, To our sister republics, To our sister republics, to those nations...' Repetition is a measure of reinforcing resources, such as Kennedy's repeated use of 
"to + object" to reinforce feelings, and the structure becomes a prose paragraph that speaks directly and clearly to the object of the speech, which seems to be much targeted and firm.

(2) 'The world is very different now. All forms of human poverty and all forms of human life.' The use of adverbs of degree intensifies the "force", emphasizing the new changes in the world situation and the high challenges to be met in the future.

(3) 'Let us never negotiate out of fear. But let us never fear to negotiate.' The excerpt begins with an imperative sentence that is strong in tone, demonstrating the American people's commitment to negotiation and support for peace.

(4) 'Let every nation know, whether it wishes us well or ill, that we shall pay any price, bear any burden, $\underline{\text { meet any }}$ hardship, support any friend, oppose any foe to assure the survival and the success of liberty.

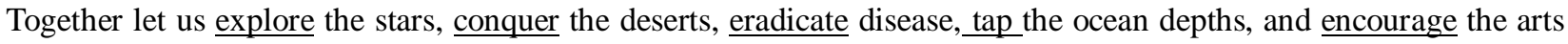
and commerce.'

The prose sentence composed of several consecutive verb phrases has a strong appeal, increases the authority of his and position views, reflects his own self-confidence and optimism, transmits his bright vision of the future to the public, stimulates public enthusiasm and patriotic feelings, weakens differences, reaches agreement with the audience, and arouses resonance in order to jointly deal with the future of the nation.

(5) Finally, Kennedy repeatedly used some words in the speech, such as we, my fellow citizens, let both sides, etc., which on the one hand played a role in strengthening the language and enhancing the impact, and on the other hand also drew the distance between the president and the people, showing his willingness to work with his own people to promote world peace.

\section{CONCLUSION}

In this paper, Martin's appraisal theory is used as the theoretical framework to analyze Kennedy's Inaugural Address from the attitude, engagement and graduation systems. Through the analysis, the author has the following findings: firstly, under the framework of appraisal theory, the judgment resources in the attitude system are highlighted, expressing rich emotions. Through analysis, the author believes that Kennedy's inaugural address makes full use of adjectives and adverbs as resources for appreciation and judgment to convey his views on the current situation. Secondly, in the engagement system, the dialogic construction resources in the heterogloss system stand out, and the speaker is more inclined to show the right and establish a stable relationship with the audience, and the author believes that President Kennedy makes great use of monogloss and heterogloss measures to regulate the responsibility and obligation of his speech or to enhance the credibility of his words, so that the words appear objective and fair, persuasive, straightforward. Finally, in the graduation system, the "force" is on strength, and the speaker uses more gestures to increase the intensity of the discourse. Therefore, it is found that President Kennedy used various prose structures, repetition and other rhetorical devices in his speech to strengthen the force of speech and enhance the effect of expression, thus making the speech one of the most successful political speeches in history. To sum up, this paper demonstrates the feasibility of appraisal theory in analyzing a special political speech, the Inaugural Address of the President of the United States, and takes President Kennedy's Inaugural Address as an example to make a detailed analysis, which enriches the study of the Inaugural Address of the President of the United States and provides valuable insights for Chinese and foreign scholars to express the meaning of evaluation effectively in relevant academic writing. It also provides valuable insights for Chinese and foreign scholars to effectively express the meaning of evaluation in related academic writing.

\section{REFERENCES}

[1] Bao Guangxia. (2012). Discourse Analysis of Interpersonal Functions in Speeches: An Example of Stevenson's Speech for President of the United States. Science and Technology Information 6, 332-333.

[2] Hu Zhuanglin, Zhu Yongsheng, Zhang Delu. (2005). Introduction to Systemic Functional Linguistics. Beijing: Peking University Press.

[3] Liu Song, Luo Xuejuan. (2017). A study on the discourse of British Prime Minister David Cameron's inauguration speech from the perspective of evaluation theory. Journal of Shandong Vocational College of Commerce and Technology 17.4, 97

[4] Martin J. R., Rose David. (2003). Working with Discourse. London \& New York: Continuum.

[5] Martin J. R. \& P. R.R. White. (2005). The Language of Evaluation: Appraisal in English. London Palgrave.

[6] Tong Wentian. (2015). Interpreting Michelle Obama's speech at Peking University from the perspective of commentary theory. Journal of Shandong Radio and Television University 1, 84

[7] Wang Zhenhua. (2001). Evaluation Systems and Their Operation - New Developments in Systemic Functional Linguistics. Foreign Languages 3,6.

[8] Yang Tingting. (2009). Yin Tiechao. Analysis of positive discourse in political speeches. Journal of Qiqihar University 9 , 101-103.

[9] Zeng Yaping. (2009). Interpreting Obama's presidential election victory speech from the perspective of critical discourse analysis. Foreign Language and Foreign Language Teaching 2, 19-21. 
Yan Tan was born in Chongqing, China in 1997. She received her Bachelor's Degree in English from Yangtze Normal University, China in 2019.

She is currently a master's student in English Education in the School of Foreign Languages, Chongqing Normal University, Chongqing, China.

Her research interests include English Education and American literature. 